\title{
Teaching Geometric Dimensioning \& Tolerancing by Using An Algorithm to Implement the Datum-based Model
}

Dr. Wangping Sun, Oregon Institute of Technology

Dr. Wangping is a professor of Oregon Institute of Technology.

\section{Prof. Yanqing Gao, Oregon Institute of Technology}

Yanqing Gao is an associate professor in the Mechanical, Manufacturing Engineering and Technology Department at Oregon Institute of Technology. She received a PhD degree from the University of Arizona, and MS degrees from the Arizona University and Southern Illinois University respectively. She was a visiting assistant professor in Transportation Active Safety Institute (TASI) at Indiana Purdue University Indianapolis and a researcher and adjunct assistant professor in University of Arizona. 


\title{
Teaching Geometric Dimensioning \& Tolerancing by Using the Algorithm
}

\author{
to Implement the Datum-based Model
}

\begin{abstract}
Geometric Dimensioning and Tolerancing (GD\&T) is a critical part in mechanical and manufacturing design. So far, the GD\&T process can only be accomplished manually with limited help from computer-aided tools. The whole process is tedious. To automate the GD\&T process has many positive impacts on boosting both the effectiveness of student learning and competitiveness of the manufacturing industry. A datum-based model for practicing GD\&T has been developed. In this paper, the authors will introduce an algorithm to automate the implementation of the datum-based GD\&T model. Both the model and the algorithm were used in teaching GD\&T. The course assessment was done in 2018 and 2019. The assessment fulfilled expectations.
\end{abstract}

\section{Introduction}

The quality of a part is dependent on the geometric specification (ideal target geometry and tolerance) of its components. Geometric Dimensioning and Tolerancing (GD\&T) is an important step in product design ${ }^{[1]}$. Tolerance modelling has been a topic of research for many years ${ }^{[2]}$. So far, ten GD\&T representation models have been developed in the public domain, which include EXPRESS model, surface graph model, representational primitive model, TTRS model, UML model, XML model, category theory model, GeoSpelling model, relationship model and ontology-based model ${ }^{[3]}$. All these models must be implemented manually and are lack of automation.

Researchers have been trying to translate the GD\&T rules into the language that can be recognized by computer. If successful, the tolerancing process can be completed by computer ${ }^{[4]}$. The researchers categorized the automation sophistication of the GD\&T process into three levels. At the first level, GD\&T primarily focuses on how to assemble the parts together; at the second level, GD\&T will automatically reflect design intent and part functionality; at the third level, GD\&T will be optimized to reduce the manufacturing cost ${ }^{[5]}$. Efforts have been invested to synthesize the GD\&T specifications by using computer. The research has been focusing on the study of GD\&T relationships of assemblies rather than a single part.

The GD\&T process remains as a tedious activity ${ }^{[6]}$. The computer-aided design (CAD) software is lack of interaction functionality to tell the user where a GD\&T specification should be placed on the engineering drawing ${ }^{[7]}$. Sun et al have developed a datum-based model to address this issue $^{[1]}$. According to their research, the GD\&T specifications of a single part can be systematically applied with clarity and conciseness. As the follow-on research, this paper will introduce an algorithm that implements the model. In the following sections, the algorithm will be described in detail and applied onto a part with patterned holes. Following that, another example is given to demonstrate the effectiveness of computer realization of the algorithm. In the 
end, the students' comments on learning outcomes and the thoughts on future research will be provided.

\section{The algorithm to implement the datum-based GD\&T model}

The datum-based GD\&T model as shown in Figure 1 goes through six layers to place GD\&T specifications on a part (Sun, 2018). The six layers are: 1) datum setup; 2) basic dimensions to locate the features to be controlled; 3) part overall sizes and feature sizes; 4) applying ASME rule 1 and geometric form tolerances; 5) applying ASME rule 2; and 6) applying other geometric tolerances such as composite tolerances.

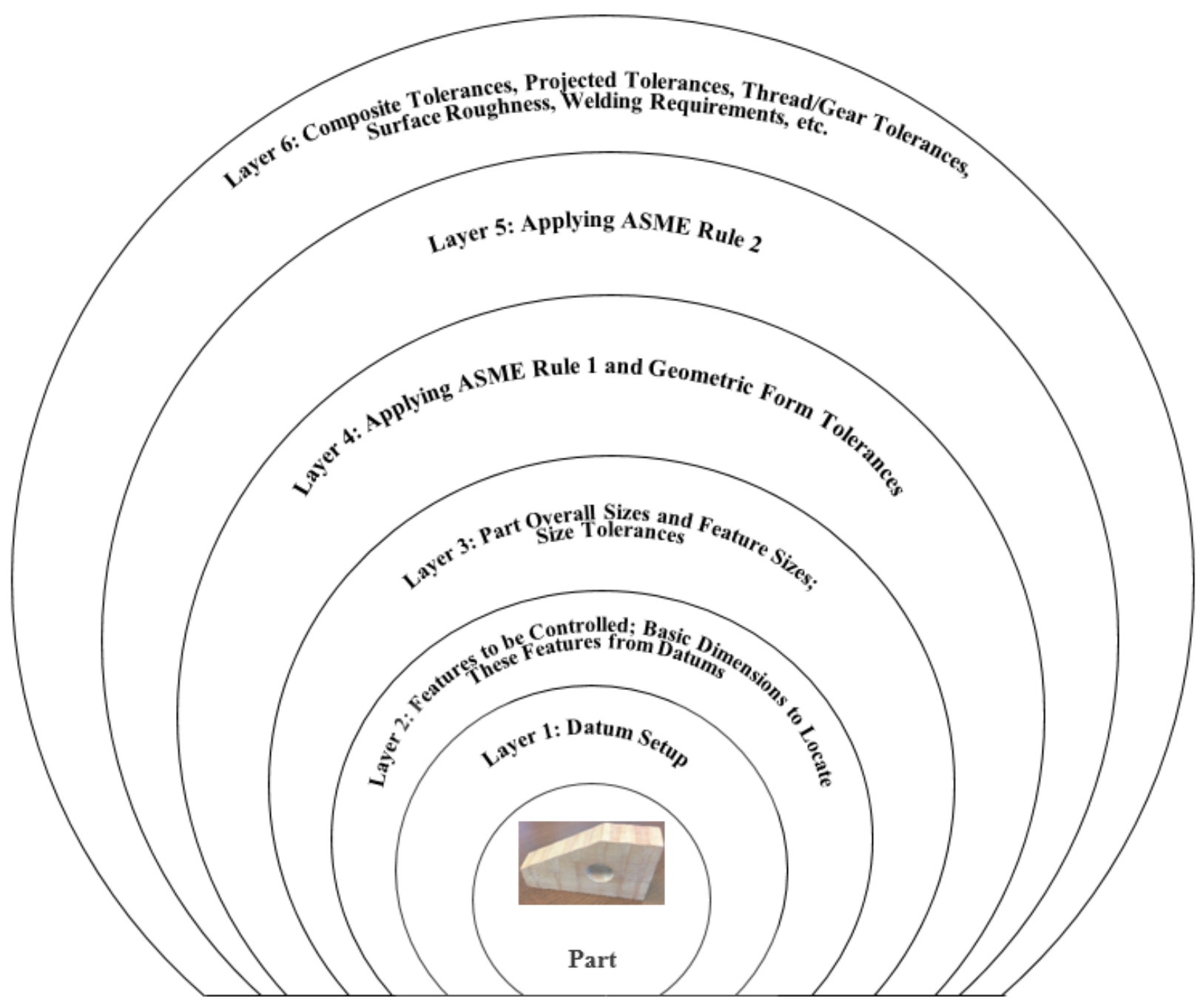

Figure 1. Datum-based GD\&T Model [Sun and Gao, 2018]

The algorithm to implement the model is displayed in Figure 2. It is in the format of a flow chart. The corresponding layers of the datum-based model are attached to the left of the flow chart. 


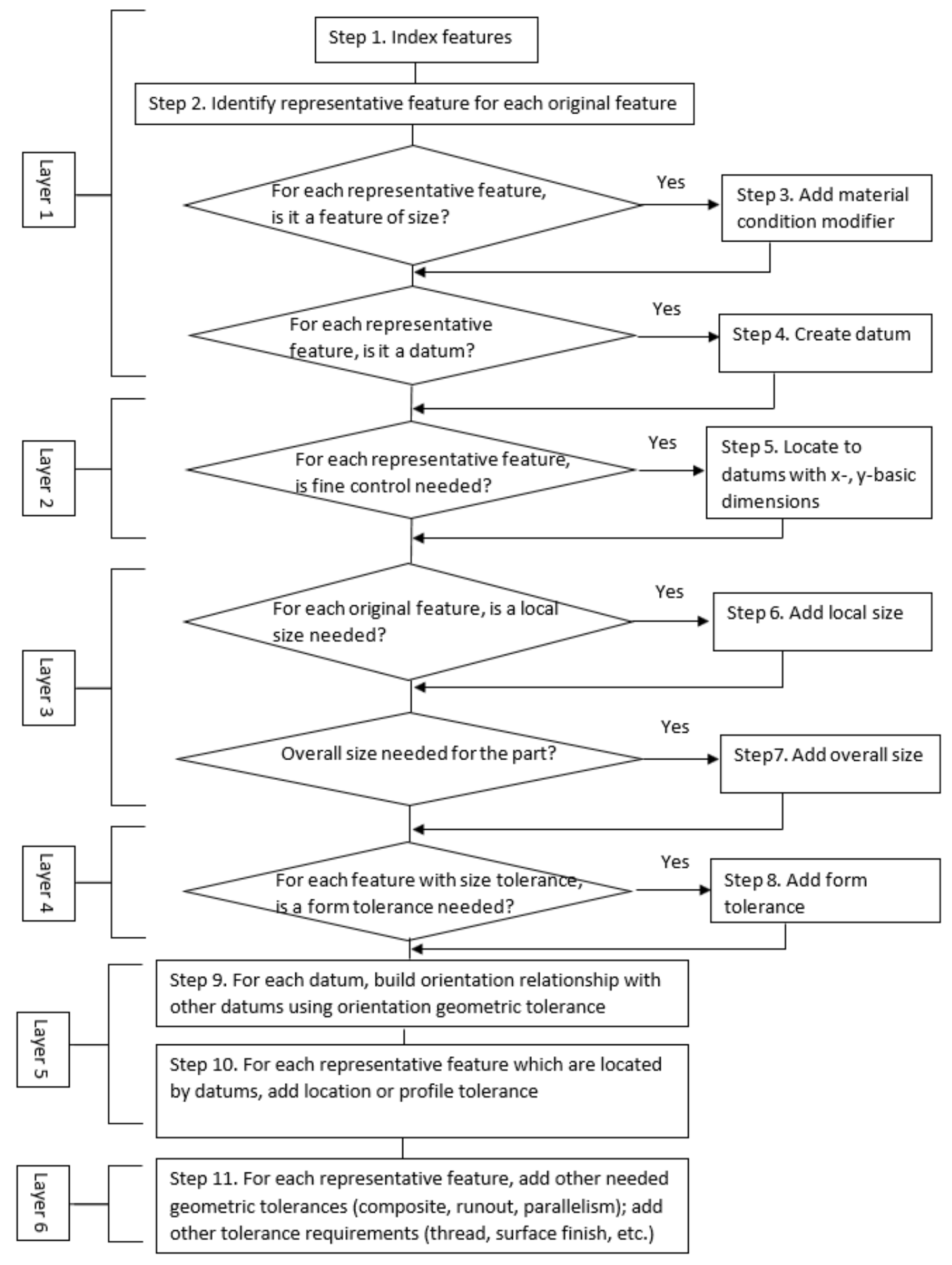

Figure 2. The algorithm to implement the datum-based GD\&T model

As shown in Figure 2, Steps 1 to 4 implement the tasks of the first layer, the Datum Setup Layer, of the datum-based GD\&T model. In this layer, all the necessary datums should be established. 
These datums will be used to locate other features that need fine tolerance control. Since the datums are also the features of the part, Step 1 of the algorithm studies the CAD drawing and index all the features. The index serves as an identification of the feature for computer programming purpose only. The algorithm defines a "feature" in a similar way as CAD defines a block. A feature used by the algorithm in this paper refers to a group of objects that can be treated as a single component and controlled by the same geometric tolerance. A feature can be a surface, a hole, a pair of symmetric surfaces, a profile, a slot, a group of patterned features, etc. With such a definition, the features of a part are considerably consolidated and the number of the features to be handled by the algorithm is significantly reduced. The relationships among the features also become much simplified.

As an example, Figure 3 shows a regular part with five holes (a bigger one and four smaller ones). Eight features are indexed as follows:

In the front view,

- Feature 1: top surface

- Feature 2: right surface

- Feature 3: bottom surface

- Feature 4: the four patterned holes

- Feature 5: left surface

- Feature 6: the bigger hole

In the side view,

- Feature 7: left surface

- Feature 8: right surface

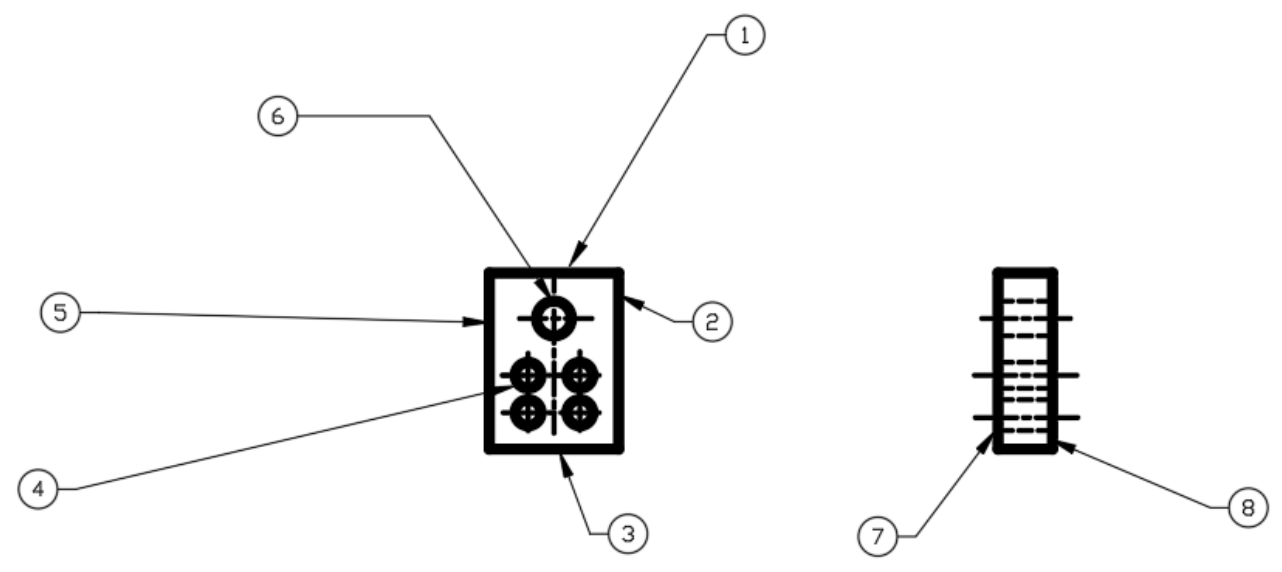

Figure 3. Indexing Features on the Part

Since a datum can be a surface, a center axis of a circular feature or the center of a group of patterned features, this paper created a concept of representative feature. A representative feature serves as the symbol for the original physical feature and it can be used to represent this feature. 
For example, the representative feature of a surface (or a fillet, chamfer, datum target) is the feature itself while the representative feature of a hole (or a shaft, slot, key, conic feature, a group of symmetric features, a group of patterned features) is its center (i.e. center axes or center planes).

In Step 2, the algorithm checks the shape of each original feature of a part to decide if a representative feature should be created. If the representative feature is the original feature itself, then the algorithm does nothing, and the representative feature will share the same index as the original feature. When the representative feature is a center, the algorithm will create a new representative feature by adding a prime to the index of the original feature. After checking the original features in Figure 3, two representative features, Feature 4' and Feature 6', are created as shown in Figure 4. These two features are the center axis of Feature 6 and the center of the patterned holes (Feature 4) respectively.
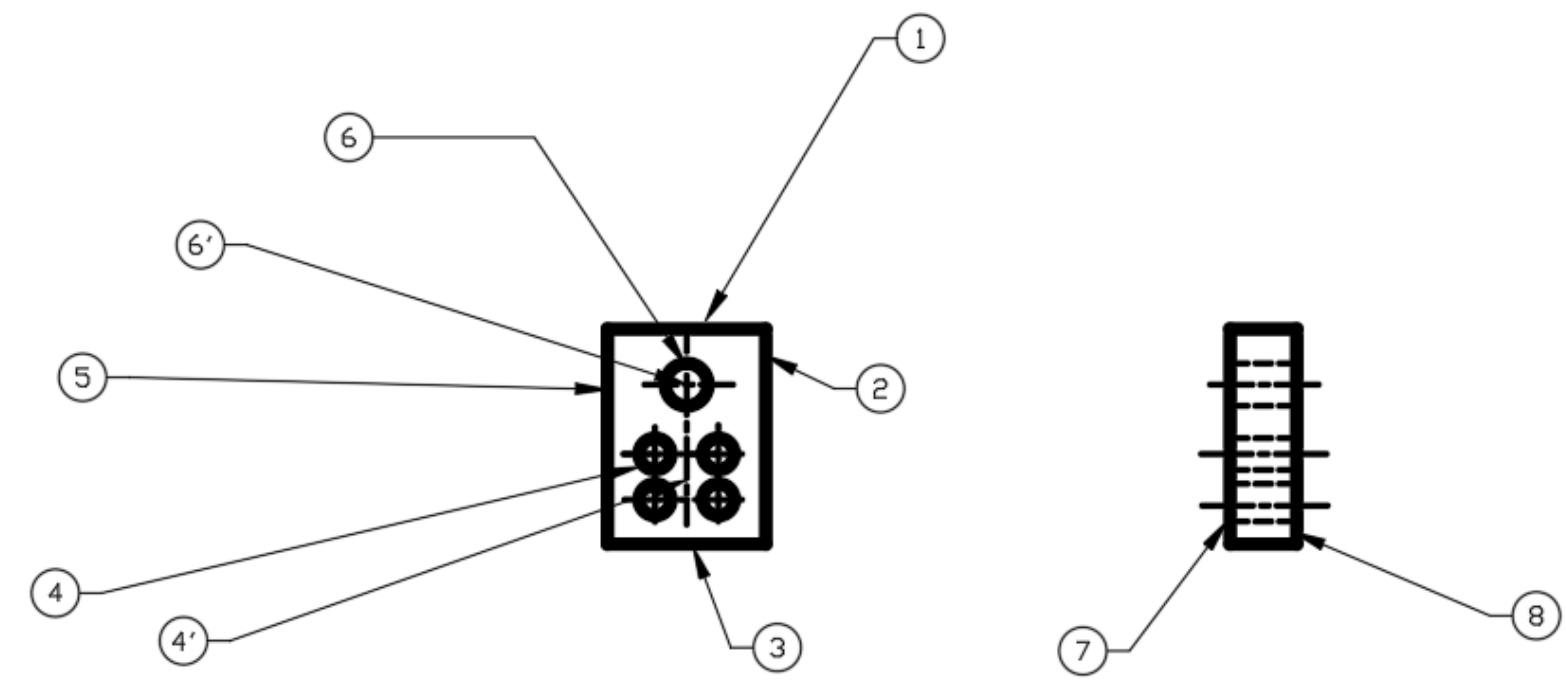

Figure 4. Two representative features, Features 4' and 6', are created

When the representative feature is itself, the feature can often be treated as regardless of feature size (RFS) and no material condition needs to be considered. When the representative feature is a center, it is often associated with feature size and a material condition should be considered. As illustrated in Figure 4, the representative feature of Feature 3 (the bottom surface) is itself. So, when it is used as a datum or controlled by a geometric tolerance, no material condition needs to be considered for such a feature. Whereas, Feature 4' is the center of the patterned holes and Feature 6' is the center axis of the hole. When these two features are used, their material conditions should be considered. After the algorithm creates all the representative features in Step 2, Step 3 of the algorithm will automatically label the representative features that are associated with size with material condition modifiers.

Step 4 of the algorithm provides a full list of the representative features of the part, by which user can decide which representative features can be chosen as datums. After Step 4 is done, four datums are built. As shown in Figure 5, Datum A is the right surface in the part's side view; 
Datums B and C are the bottom surface and the left surface of the part in its left view; Datum D is the center axis of the large hole.
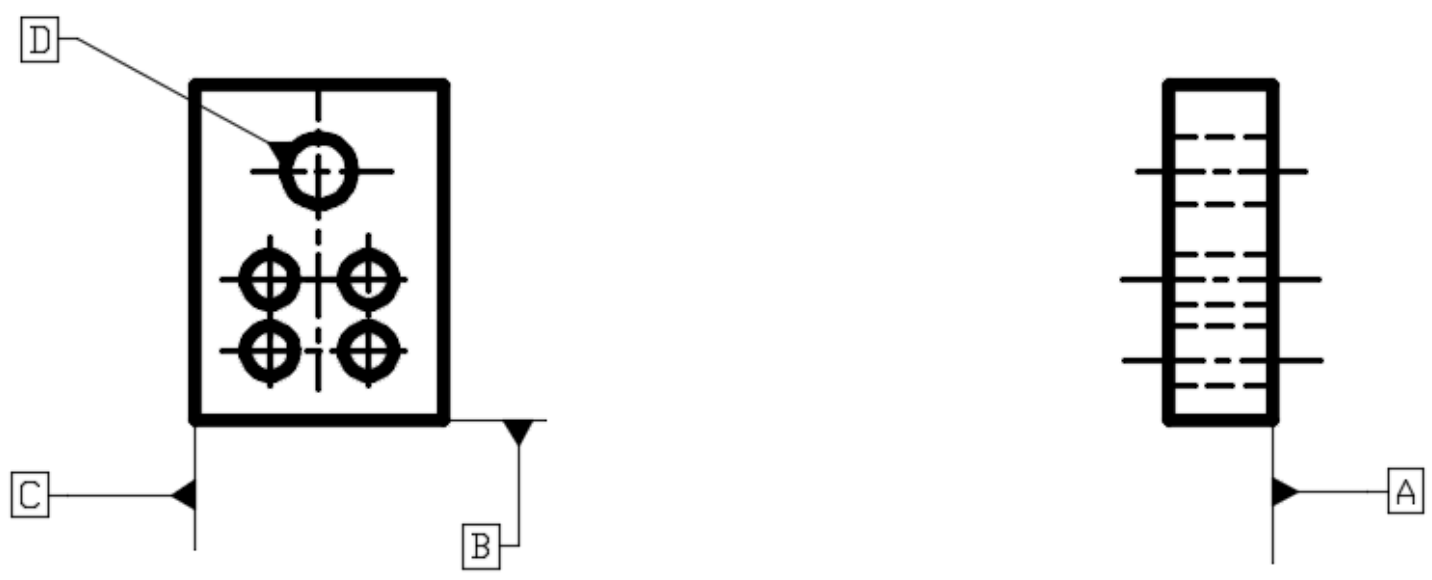

Figure 5. Datum establishment

After the datums are set up, Step 5 of the algorithm implements the second layer of the model by identifying and locating the features from the datums. This process applies to the datum features or other features that must be controlled by feature control frames. Basic dimensions with reference to the established datums are used to locate these features. The algorithm prompts each representative feature to user and asks if the feature needs to be located by the basic dimensions. If basic dimensions are needed, then the algorithm will list all the available datums from which user may choose. As shown in Figure 6, the large hole is positioned 5.038" off Datum B and 2.500" off Datum C. The smaller patterned holes are located by 1.500" off Datum C and 2.195" off Datum D.

The algorithm will automatically notify the human user that, if the feature group has a pattern, the basic dimensions should also be added to indicate the location of each member feature with reference to other members in the pattern. In Figure 6, the four small holes are arranged in a rectangular pattern. The basic dimensions, 2.000" and 1.443", are used to show the locations of these holes in horizontal and vertical directions. 

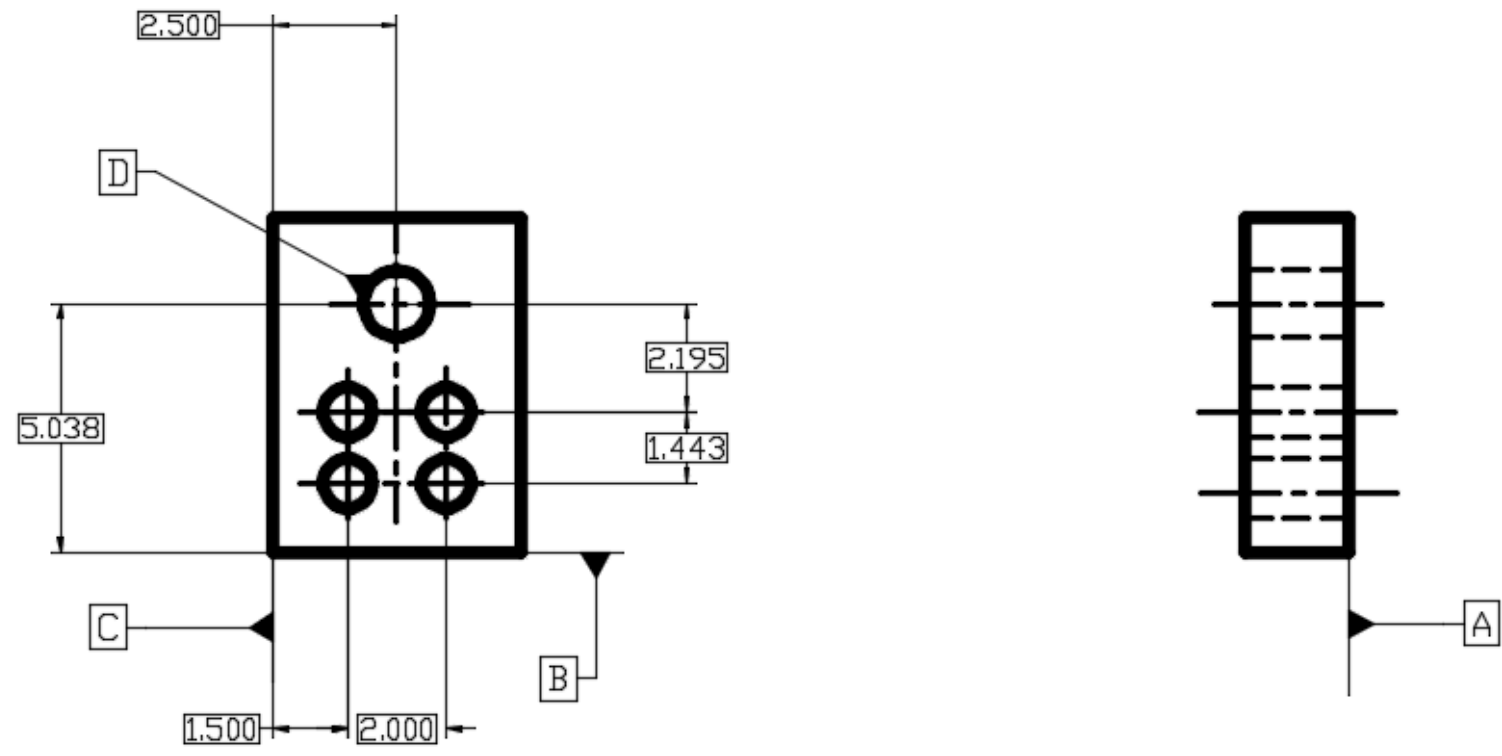

Figure 6. Locating Datum D and patterned holes with basic dimensions

The third layer of the model is to define sizes, which is accomplished by Step 6 and Step 7 of the algorithm. There are two types of sizes of a part, the local size and the overall size. A local size reflects the size of a smaller feature that is located on the bigger part. A local size normally refers to the feature size of a hole, shaft, counter-bore diameters/depths, slot sizes, etc. An overall size reflects the full dimension (such as total length, height or width) of the part. A size dimension should have a size tolerance. For simplicity, this paper uses .005 " as the tolerance applied to entire dimensions.

In Step 6, the algorithm goes through all the original features and asks user if a local size is needed for that specific feature. In Step 7, the algorithm goes through the original features which do not have a local size and asks user if an overall size needs to be applied on. The basic dimensions added by Step 5 and the size dimensions added by Steps 6 and 7 should make the whole part fully dimensioned. As shown in Figure 7, two local sizes, $\varnothing 1.342$ " for the large hole and $\varnothing 1.000 "$ for four small holes, and the overall size of the part, 5.000" (width) x 6.794" (height) x 2.104" (thickness) are added to the drawing. 

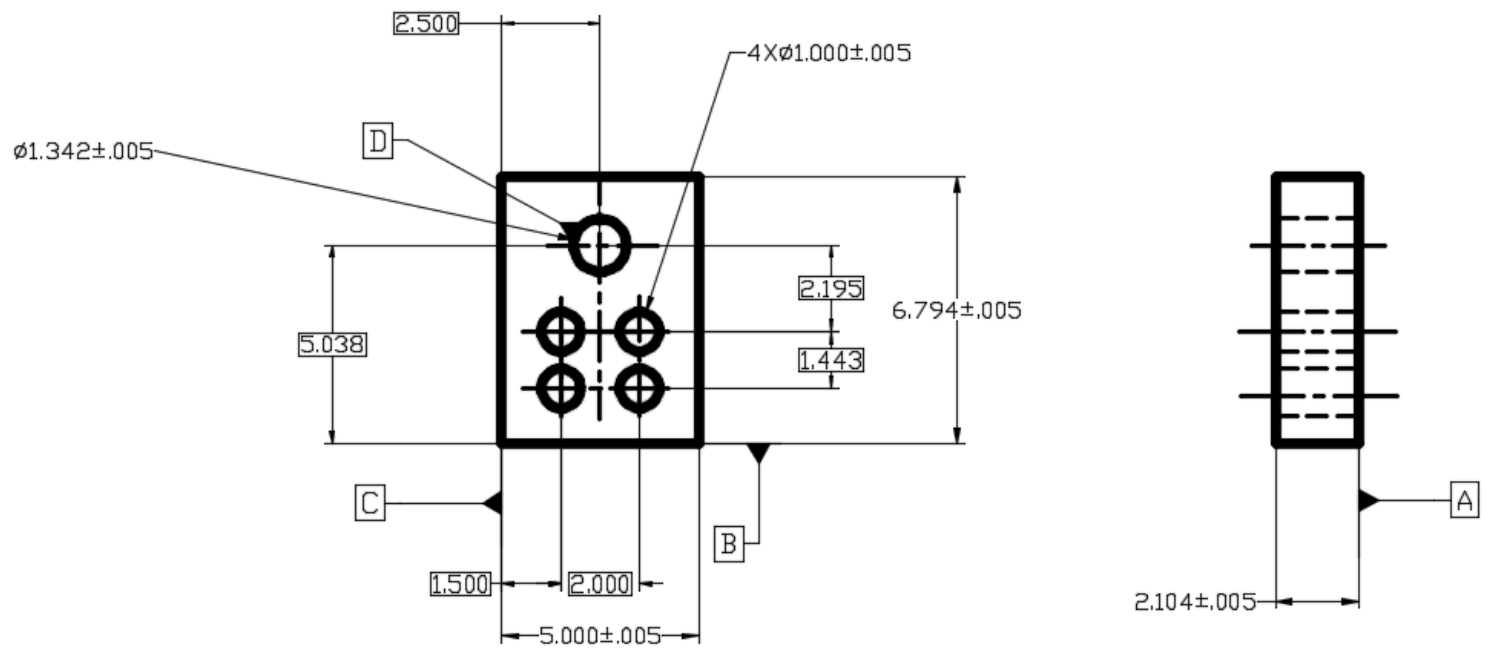

Figure 7. Dimensioning the part with local sizes and overall Sizes

Step 8 of the algorithm finishes the task of the fourth layer of the model, which is to control the form of the features associated with size as required by ASME Y14.5-2009 Rule 1. The algorithm goes through the features associated with size (i.e. the features with local size or overall size) and asks user if a form tolerance is needed. As illustrated in Figure 8, the form tolerance (.002") is applied to control the flatness of Datums A, B and C. For simplicity purpose, the holes are not applied with form tolerance.
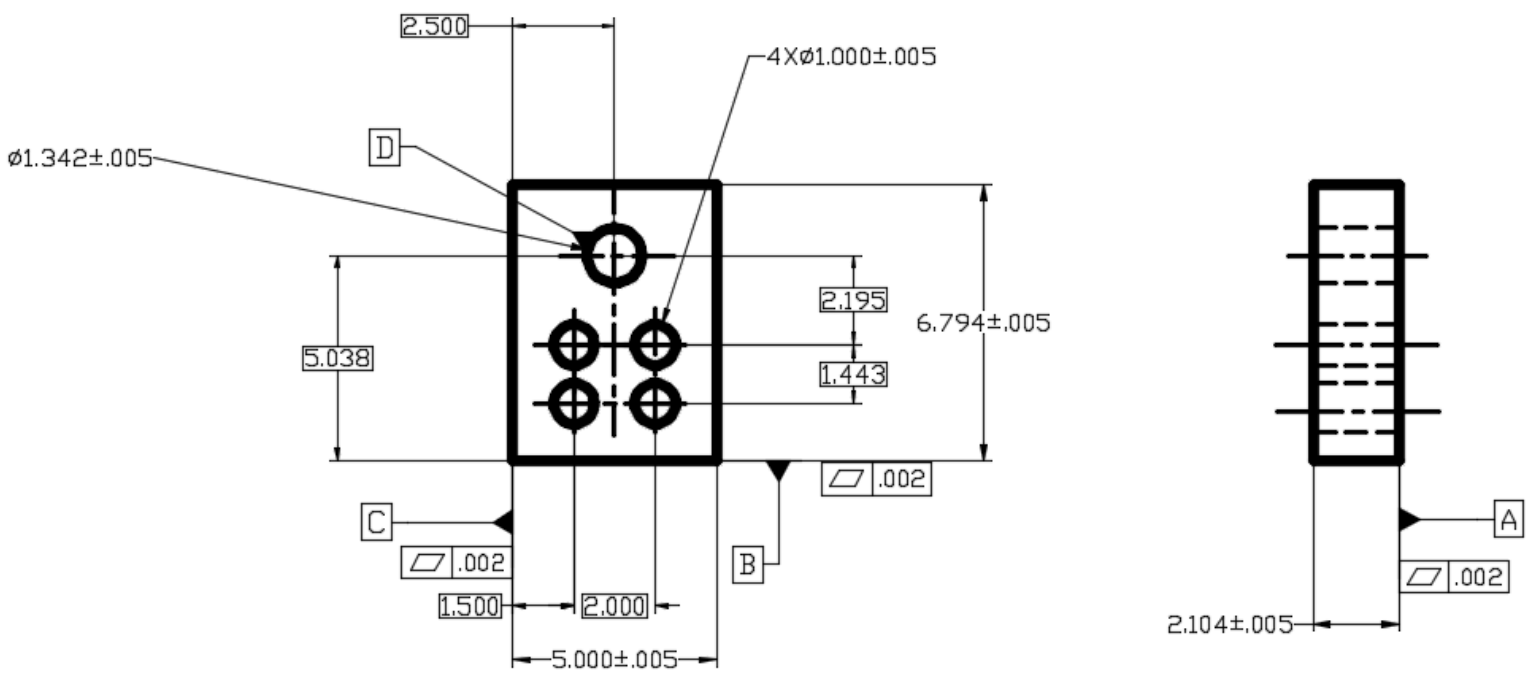

Figure 8. Applying form tolerances to features associated with size

The next layer of the datum-based model, Layer 5, is to apply ASME Y14.5-2009 Rule 2. The algorithm finishes the tasks of Layer 5 in Step 9 and Step 10. In Step 9, the algorithm first browses all datums (and datums only) to let user build the orientation relationships (perpendicularity or angularity in most cases) among datums. Then, the algorithm automatically 
browses all other features which have been located with basic dimensions in Step 5 to apply location or profile tolerance with reference to each feature's locating datums. Since Step 3 of the algorithm has already determined the features of size, Step 9 and Step 10 directly utilize the result. Wherever a feature of size is processed, user will be prompted by the algorithm that a material condition (MMC/MMB, LMC/LMB or RFS) may be added in the feature control frame. To make the algorithm simple, it is up to user to specify which material condition should be adopted.

Figure 9 (a) shows the work completed by Step 9 in which a perpendicularity tolerance (.003") is added on Datum B and Datum C respectively and a perpendicularity tolerance (.001") with MMC added on Datum D. Figure 9 (b) shows the work completed by Step 10 in which the position tolerances (.002") for the bigger hole and four smaller holes with MMC applied onto the features and Datum D.
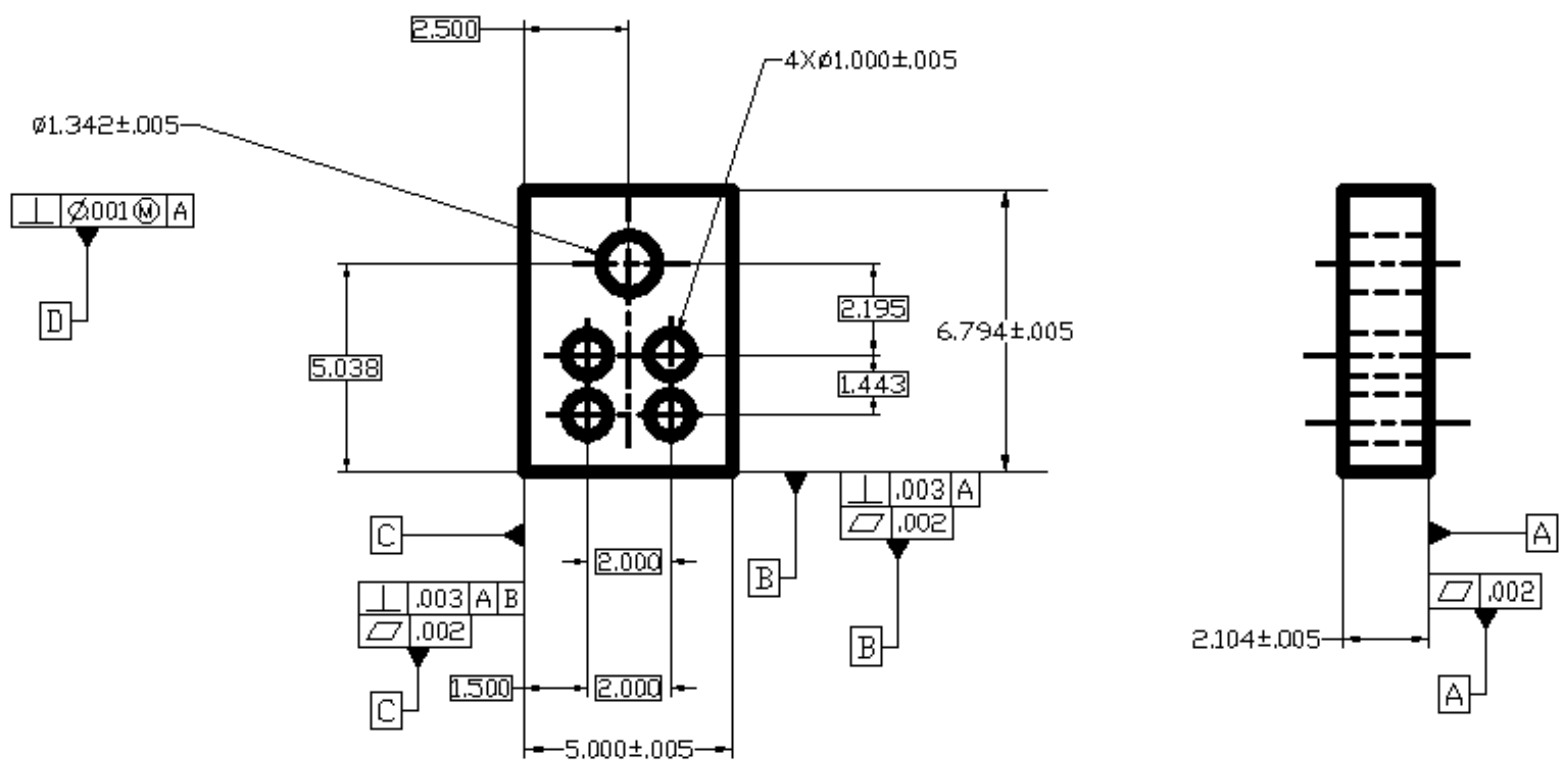

(a) 

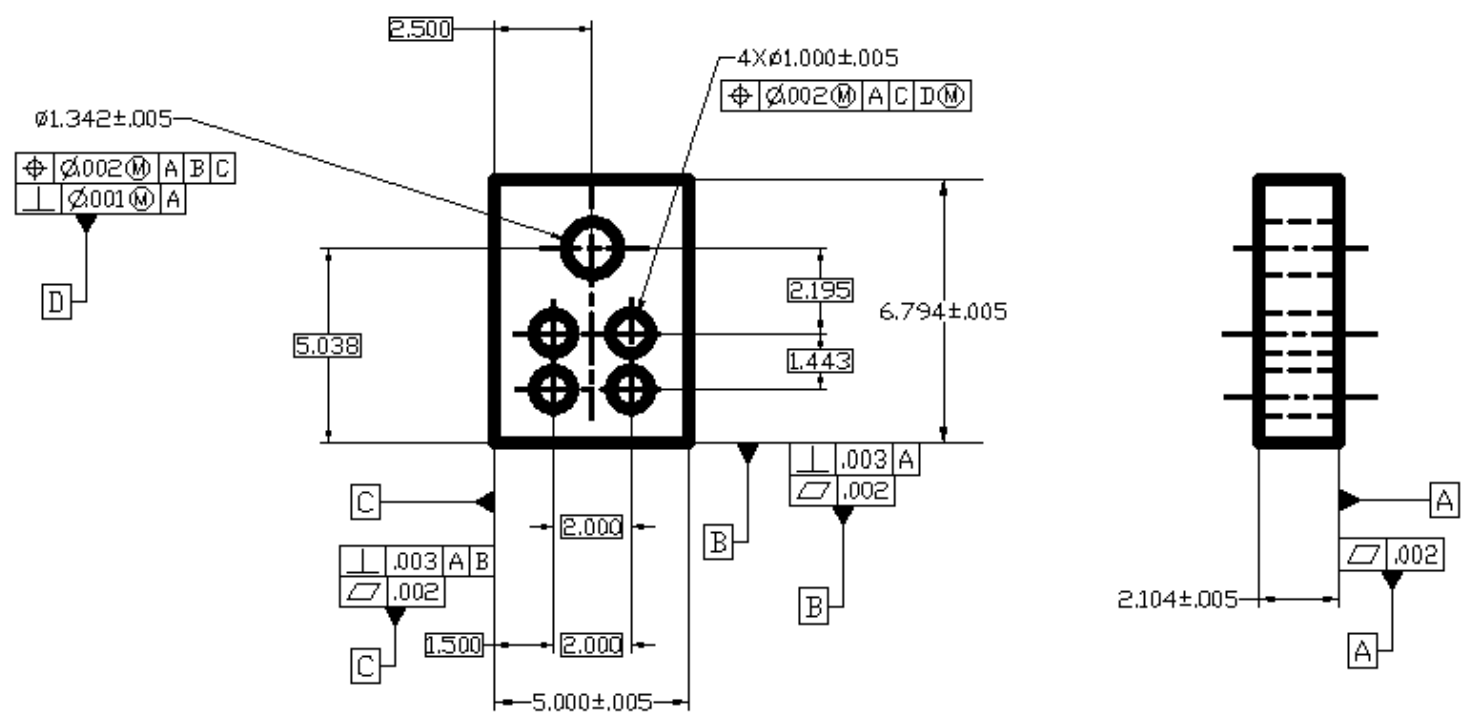

(b)

Figure 9. Applying ASME Y-14.5-2009 Rule 2

Step 11 of the algorithm is to implement the last layer of the model, Layer 6, which applies other tolerances (such as parallelism, composite tolerance, runout) to the remaining features to be controlled. As an example, Figure 10 displays that a parallelism tolerance (.002") is applied onto the top surface and a composite tolerance to the four smaller holes (position tolerance $\Phi .001$ "). After Layer 6 is completed, all the GD\&T specifications will be placed on the part.
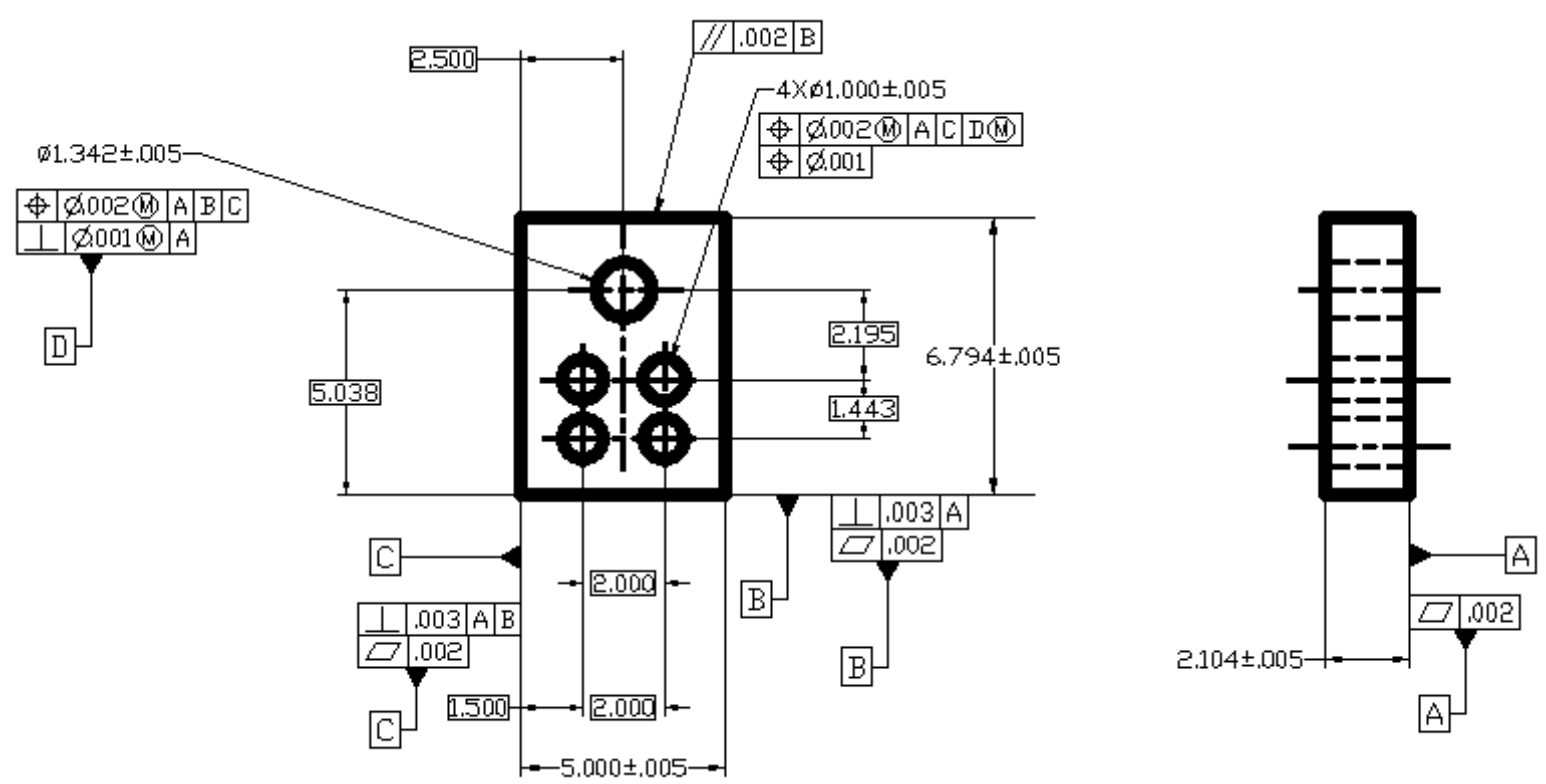

Figure 10. Applying parallelism and composite tolerances 


\section{Computer realization of the algorithm}

A GD\&T tool has been developed by using Visual Basic Application (VBA) to implement the algorithm. As illustrated in Figure 11, a graphic user interface (GUI) has been designed to interact user with the software. This GUI has seven tabs to implement the algorithm. The GUI interacts with user to index the features, identify their representative features, choose datums, identify the features which are to be located by the datums, apply the local sizes to the needed features, apply the overall sizes for the part, and apply ASME Rule 1 and Rule 2 to the needed datums and features. After all these tasks are done, the GD\&T tool will provide the outcomes on an Excel spreadsheet.

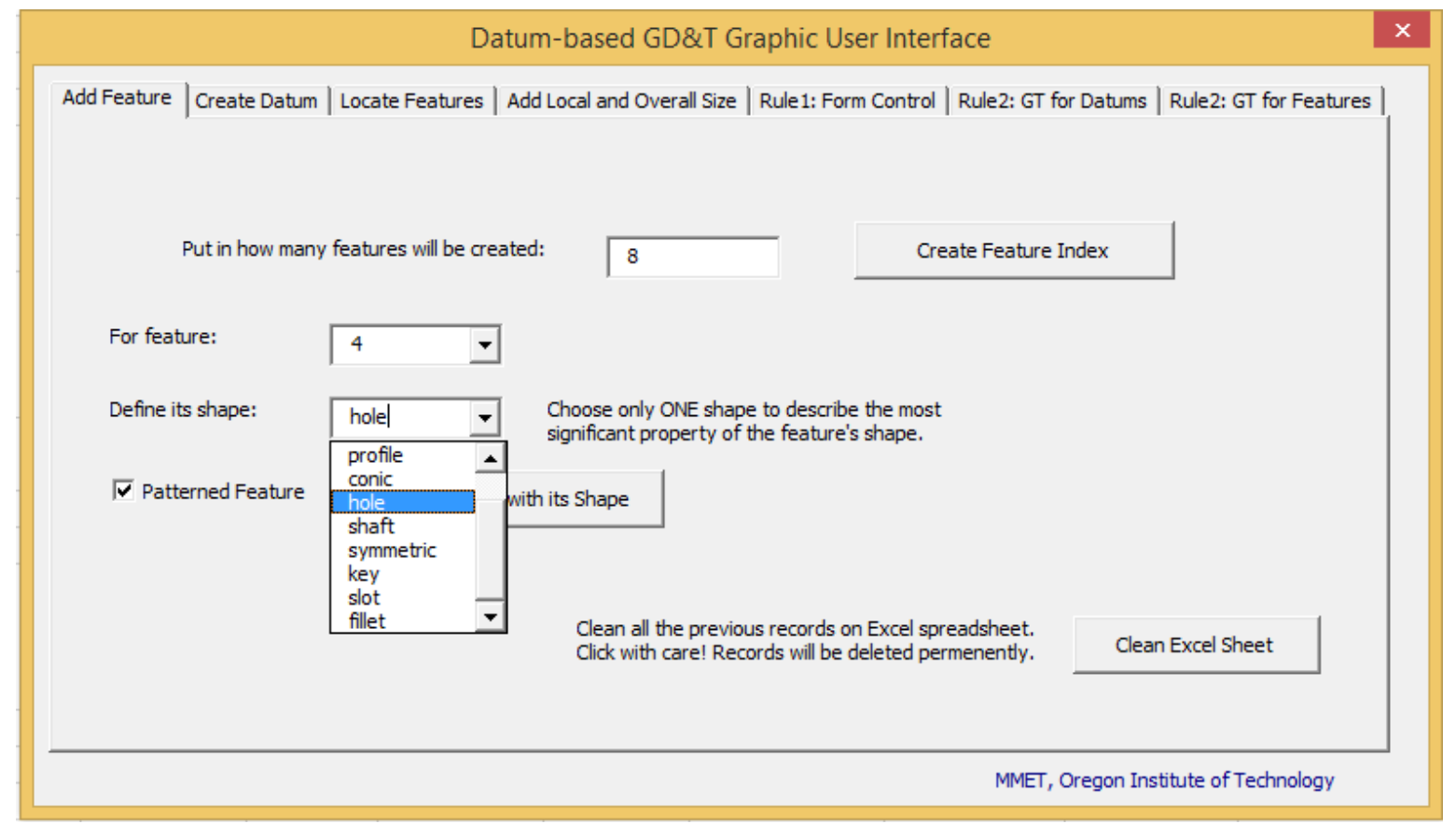

Figure 11. The GUI of the GD\&T tool that implements the algorithm

Figure 12 displays the output after the GD\&T tool is used to analyze the part in Figure 3 . The interpretation of the output for some exemplary features is listed below:

- Feature 1: original feature and representative feature are the same; it does not have material condition; an overall size is needed from Feature 1 to Feature 3; a parallelism (or perpendicularity) tolerance is needed in reference to Datum B, which is Feature 3.

- Feature 3: original feature and representative feature are the same; it does not need to have a material condition; it is a datum, which is Datum B; a form tolerance is needed for this feature; an overall size is needed from Feature 1 to Feature 3; a perpendicularity tolerance is needed in reference to Datum A, which is Feature 8.

- Feature 4: original feature group has a pattern; it is a group of holes; it needs a local size with size tolerance; 
- Feature 4': created automatically by the software; material condition should be considered when this feature is used; basic dimensions in reference to Datums C and D are needed; basic dimensions among the member features are needed since this is a patterned feature group; location tolerance is needed in reference to the datum and when tolerance is placed, adding a primary datum should be considered; composite location tolerance is needed for this feature.

- Feature 6: original feature is a hole; local size with size tolerance is needed.

- Feature 6': created automatically by the software; material condition should be considered when this feature is used; this feature is a datum, which is Datum D; basic dimensions off Datums B and C are needed; location tolerance reference to the datums are needed while in the same time, consider adding primary datum when tolerance is placed; a perpendicularity tolerance is needed reference to Datum A, which is Feature 8.

Figure 12 shows the output of the GD\&T tool. By following these instructions, GD\&T specifications are put onto the part, which has been demonstrated in Figure 10.

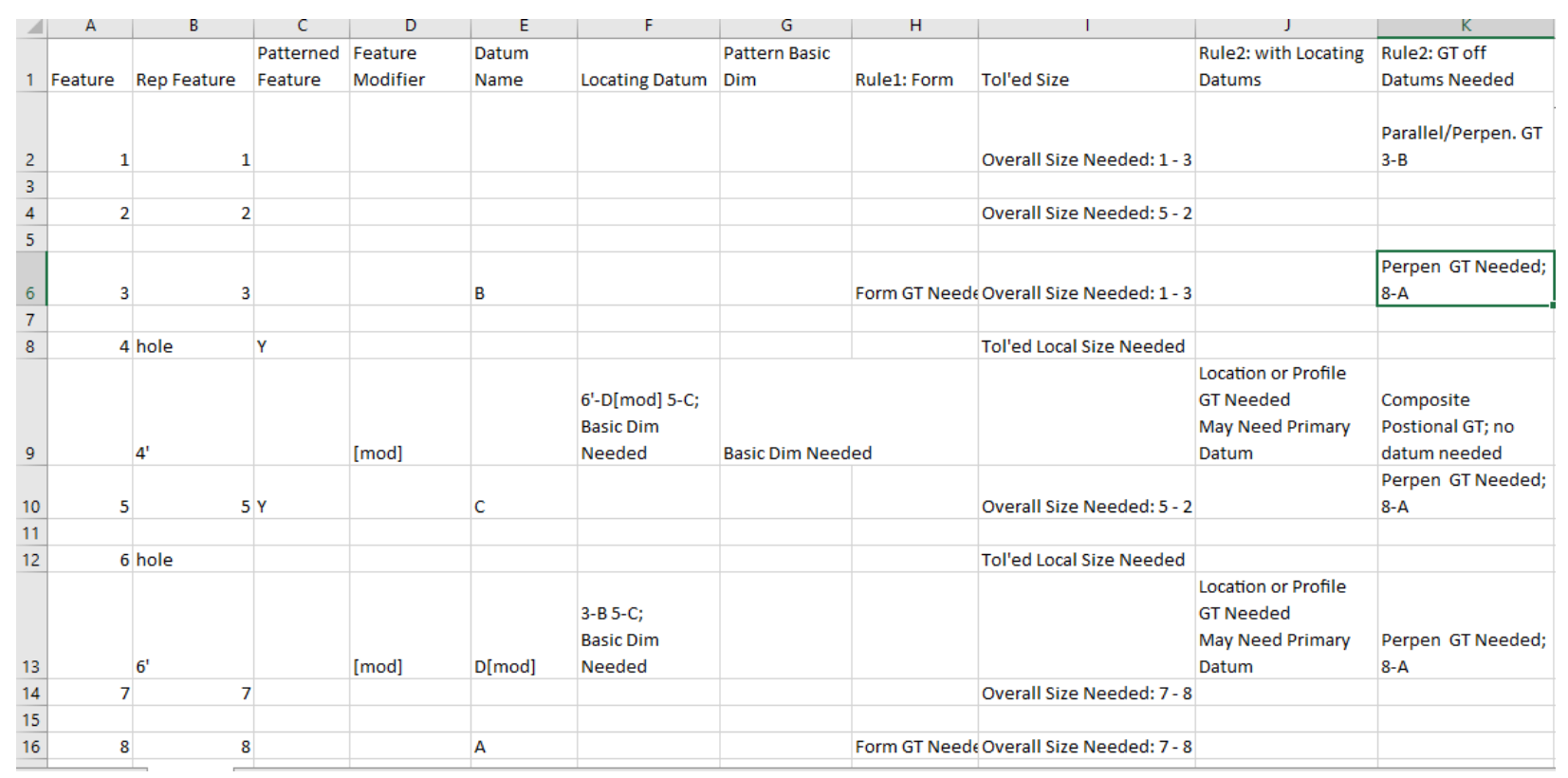

Figure 12. The output of the GD\&T tool

\section{The course assessment}

The students are given the software to practice GD\&T. Figure 13 shows an example of a student project. In this project, the students were required to practice GD\&T on a cylindrical part with three fins. The 3D model of the part is displayed in Figure 13 (a). After using the GD\&T tool, the GD\&T specifications are placed in Figure 13 (b). 

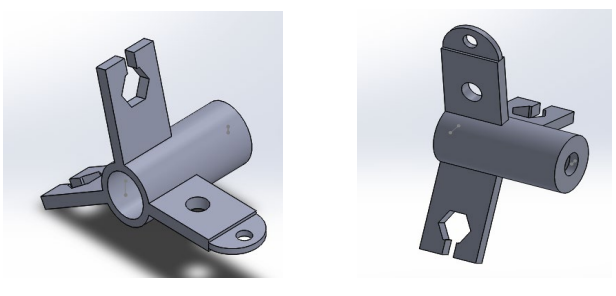

(a)
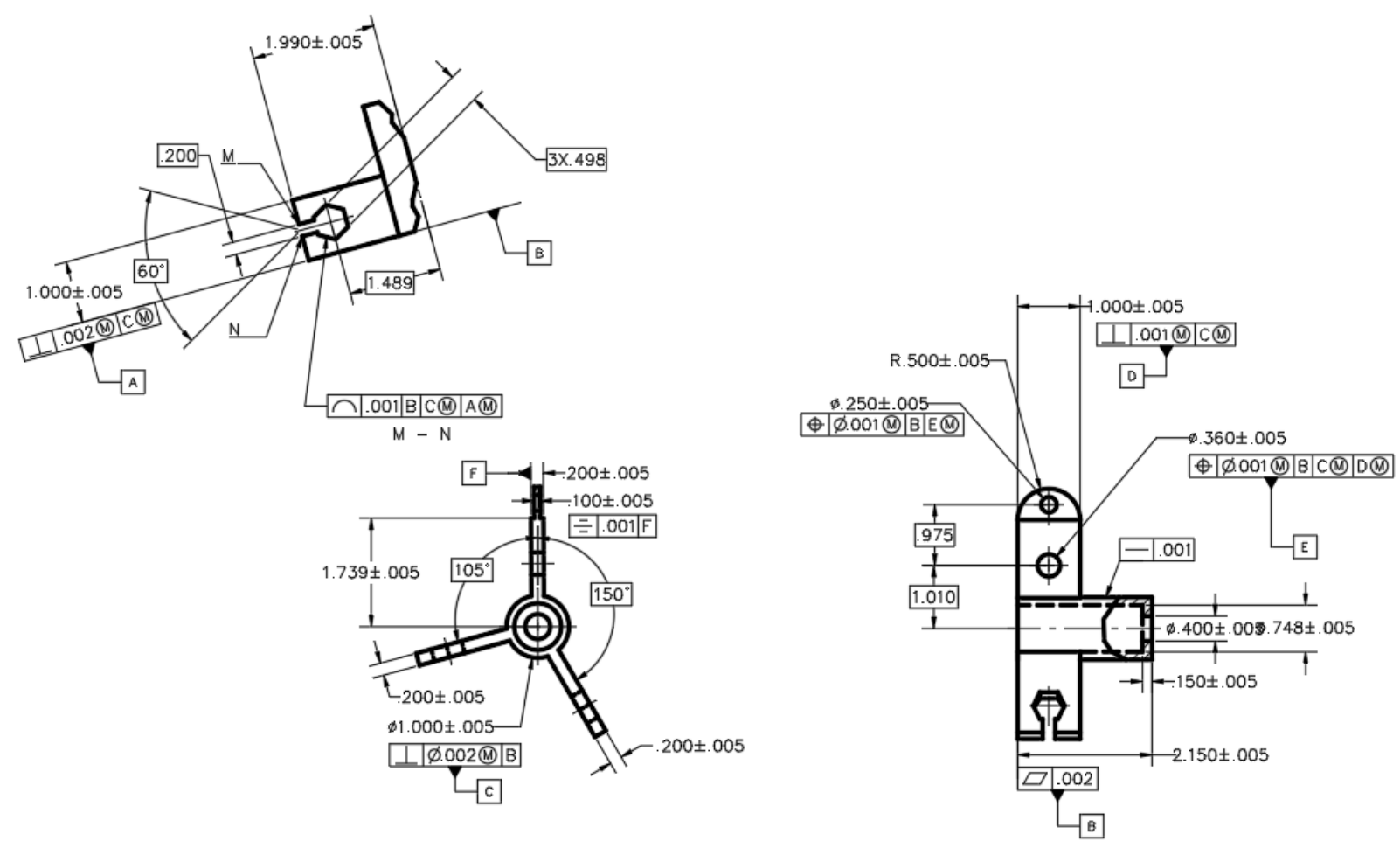

(b)

Figure 13. GD\&T specifications created by using the GD\&T tool

The course was first assessed by following the ABET ETAC Student Outcomes (a) and (b) in 2018. The sample data were collected from the students pursuing Engineering Technology degrees in mechanical and manufacturing engineering. The initial assessment result was satisfactory and was published in another paper (Sun and Gao, 2018). The course was assessed again in summer 2019 by implementing new ABET ETAC and EAC Criterion (3) Student Outcomes. Tables 1 and 2 list the Performance Criteria that were set up according to the ABET requirements. The assessment result was satisfactory with more than $80 \%$ of the students meeting the preset Student Outcomes. 
Table 2 (a). Assessment by using new ABET ETAC Student Outcomes.

\begin{tabular}{|c|c|c|}
\hline $\begin{array}{l}\text { ABET Student } \\
\text { Outcomes }\end{array}$ & Performance Criteria & MFG 314 Specific Requirements \\
\hline \multirow{3}{*}{$\begin{array}{l}\text { ETAC (3) an ability to } \\
\text { communicate } \\
\text { effectively with a } \\
\text { range of audiences }\end{array}$} & $\begin{array}{l}\text { Appropriate mastery of } \\
\text { modern engineering tools }\end{array}$ & $\begin{array}{l}\text { - Draw the part completely and } \\
\text { accurately with appropriate } \\
\text { computer tool }\end{array}$ \\
\hline & $\begin{array}{l}\text { Use techniques and skills } \\
\text { necessary for engineering } \\
\text { practice }\end{array}$ & $\begin{array}{l}\text { Place the GD\&T } \\
\text { specifications by following } \\
\text { the algorithm }\end{array}$ \\
\hline & $\begin{array}{l}\text { Use appropriate computer } \\
\text { tool to present engineering } \\
\text { design effectively to people } \\
\text { with various backgrounds }\end{array}$ & $\begin{array}{l}\text { Present the part layer-by-layer } \\
\text { by following the datum-based } \\
\text { model to the whole class } \\
\text { clearly and correctly }\end{array}$ \\
\hline \multirow{4}{*}{$\begin{array}{l}\text { ETAC (7) an ability to } \\
\text { acquire and apply new } \\
\text { knowledge as needed, } \\
\text { using appropriate } \\
\text { learning strategies. }\end{array}$} & $\begin{array}{l}\text { - } \begin{array}{l}\text { Identify an engineering } \\
\text { problem }\end{array} \\
\end{array}$ & $\begin{array}{l}\text { - Use 2D or 3D approach to } \\
\text { present the part }\end{array}$ \\
\hline & $\begin{array}{l}\text { - Make appropriate } \\
\text { assumptions }\end{array}$ & $\begin{array}{l}\text { - Make assumptions on the } \\
\text { quality requirements for the } \\
\text { part }\end{array}$ \\
\hline & $\begin{array}{l}\text { - Apply engineering } \\
\text { principles to analyze the } \\
\text { problem }\end{array}$ & $\begin{array}{l}\text { Use the algorithm to finish } \\
\text { GD\&T specifications } \\
\text { completely and accurately }\end{array}$ \\
\hline & $\begin{array}{l}\text { Formulate a plan which } \\
\text { will lead to a solution }\end{array}$ & $\begin{array}{l}\text { When placing GD\&T } \\
\text { specifications, go through the } \\
\text { algorithm layer-by-layer }\end{array}$ \\
\hline
\end{tabular}

Table 3. Assessment by using new ABET EAC Student Outcomes.

\begin{tabular}{|c|c|c|}
\hline $\begin{array}{l}\text { ABET Student } \\
\text { Outcomes }\end{array}$ & Performance Criteria & MFG 314 Specific Requirements \\
\hline \multirow{3}{*}{$\begin{array}{l}\text { EAC (1) an ability to } \\
\text { apply knowledge, } \\
\text { techniques, skills and } \\
\text { modern tools of } \\
\text { mathematics, science, } \\
\text { engineering, and } \\
\text { technology to solve } \\
\text { broadly-defined } \\
\text { engineering problems } \\
\text { appropriate to the } \\
\text { discipline; }\end{array}$} & $\begin{array}{l}\text { Appropriate mastery of } \\
\text { modern engineering tools }\end{array}$ & $\begin{array}{l}\text { - Draw the part completely and } \\
\text { accurately with appropriate } \\
\text { computer tool }\end{array}$ \\
\hline & $\begin{array}{l}\text { - Use techniques and skills } \\
\text { necessary for engineering } \\
\text { practice }\end{array}$ & $\begin{array}{l}\text { - } \\
\text { Place the GD\&T } \\
\text { specifications by following } \\
\text { the algorithm }\end{array}$ \\
\hline & $\begin{array}{l}\text { Use appropriate computer } \\
\text { tool to present engineering } \\
\text { design effectively to people } \\
\text { with various backgrounds }\end{array}$ & $\begin{array}{l}\text { Present the part layer-by-layer } \\
\text { by following the datum-based } \\
\text { model to the whole class } \\
\text { clearly and correctly }\end{array}$ \\
\hline $\begin{array}{l}\text { EAC (2) an ability to } \\
\text { design systems, }\end{array}$ & $\begin{array}{l}\text { Identify an engineering } \\
\text { problem }\end{array}$ & $\begin{array}{l}\text { - Use } 2 \mathrm{D} \text { or } 3 \mathrm{D} \text { approach to } \\
\text { present the part }\end{array}$ \\
\hline
\end{tabular}




\begin{tabular}{|c|c|c|}
\hline \multirow{3}{*}{$\begin{array}{l}\text { components, or } \\
\text { processes meeting } \\
\text { specified needs for } \\
\text { broadly-defined } \\
\text { engineering problems } \\
\text { appropriate to the } \\
\text { discipline; }\end{array}$} & $\begin{array}{l}\text { - Make appropriate } \\
\text { assumptions }\end{array}$ & $\begin{array}{l}\text { - Make assumptions on the } \\
\text { quality requirements for the } \\
\text { part }\end{array}$ \\
\hline & $\begin{array}{l}\text { - Apply engineering } \\
\text { principles to analyze the } \\
\text { problem }\end{array}$ & $\begin{array}{l}\text { - Use the algorithm to finish } \\
\text { GD\&T specifications } \\
\text { completely and accurately }\end{array}$ \\
\hline & $\begin{array}{l}\text { Formulate a plan which } \\
\text { will lead to a solution }\end{array}$ & $\begin{array}{l}\text { When placing GD\&T } \\
\text { specifications, go through the } \\
\text { algorithm layer-by-layer }\end{array}$ \\
\hline
\end{tabular}

Student comments were also collected and listed below:

- The model, algorithm and software provide an application structure for college students so that they can apply GD\&T in their first engineering job.

- The algorithm is a relatively conservative method. The software is easy to go through.

- The datum-based GD\&T model guides the designer with 6 layers to follow to better understand the part design intent, to validate quality specifications before the part is ever manufactured and improved.

- Each layer is systematically composed. It allows you to think about each layer individually to make sure that each feature is defined.

- The algorithm drives you to do the design right at the first time.

- Setting the datums first is great since it conceptualizes how a part should be measured. Basic dimension help you find what is important.

- It allows you to learn where to be forgiving; also adding the form features helps further conceptualize the product and what is necessary to manufacture it.

- It built a standard process for manufacturing design.

- You can start with an easy part, going through all layers. Then you can put the easy parts together to form a complicated part. And you can go through all the layers one more time.

- The system seems to function nicely in helping computerize the thought process to prevent GD\&T from being too overwhelming.

- More automation is needed, especially for complicated parts.

- It helps identify incorrect GD\&T practices, manufacturing flaws or concerns.

\section{Conclusions}

This paper has developed an algorithm to implement the GD\&T datum-based model. A computer software has been developed by which user and computer can interact to practice GD\&T. With the help of the software, the GD\&T practice is undertaken under the guidance of computer with reduced human intervention. Some GD\&T specifications are automatically recommended by the software. This is another step further to realize the full automation of GD\&T process. 
The algorithm of this paper has two contributions. The first contribution is that it defines the part components by consolidating the features. Consolidation of individual features conceptualize the relations among features in a much simpler manner, thus making the GD\&T process easier. The second contribution is that it develops the concept of representative feature. The original feature and the representative feature accept different GD\&T specifications respectively. The original feature accepts form tolerance or profile tolerance while the representative feature accepts location tolerance or orientation tolerance. The material condition is automatically created for the representative feature.

The GD\&T recommendations given by the software are currently output onto the Excel spreadsheet by the software. When putting these recommendations onto a CAD drawing, user must manually translate each recommendation into all sorts of GD\&T symbols that are recognizable by CAD software. In the future research, the authors will study how to close this gap. They will explore the possibility of converting the GD\&T recommendations into executable CAD commands so that the GD\&T symbols can be placed on CAD drawings automatically.

\section{References}

1. Wangping Sun, Yanqing Gao, 2018, A datum-based model for practicing geometric dimensioning \& tolerancing, submitted to the Journal of Engineering Technology.

2. Hesham Mahmouda, Vimal Dhokiaa, Aydin Nassehia, 2016, STEP-based Conceptual Framework for Measurement Planning Integration, 14th CIRP Conference on Computer Aided Tolerancing (CAT).

3. Yuchu Qin, Qunfen Qi, Wenlong Lu, Xiaojun Liu, Paul J. Scott, Xiangqian Jiang, 2018, A review of representation models of tolerance information, the International Journal of Advanced Manufacturing Technology, Vol. 95, Issue 5-8.

4. F. Litwa, M. Gottwalda, S. Spudeikob, K. Paetzold, M.Vielhaber, 2016, Optimization coupling approach for/with non-static point-based CAT models, 14th CIRP Conference on Computer Aided Tolerancing (CAT).

5. Sayed Mohammad Hejazi, Deepanjan Biswas, Adarsh Venkiteswaran, Jami J. Shah and Joseph K., 2016, Automated $1^{\text {st }}$ order Tolerancing: Schema Generation, Proceedings of ASME 2016 International Design Engineering Conferences and Computers and Information in Engineering Conference.

6. M. S. J. Walter, T. C. Spruegel, S., 2015, Last Cost Tolerance Allocation for Systems with time-variant Deviations, 13th CIRP conference on Computer Aided Tolerancing.

7. Pierric Leonard, Eric Pairel and Max Giordano, 2013, A simpler and more formal geometric tolerancing model, the 12th CIRP Conference on Computer Aided Tolerancing. 